\title{
More ethical and more efficient clinical research: multiplex trial design
}

\author{
Frederik Keus, Iwan CC van der Horst and Maarten W Nijsten
}

\begin{abstract}
Background: Today's clinical research faces challenges such as a lack of clinical equipoise between treatment arms, reluctance in randomizing for multiple treatments simultaneously, inability to address interactions and increasingly restricted resources. Furthermore, many trials are biased by extensive exclusion criteria, relatively small sample size and less appropriate outcome measures.

Findings: We propose a 'Multiplex' trial design that preserves clinical equipoise with a continuous and factorial trial design that will also result in more efficient use of resources. This multiplex design accommodates subtrials with appropriate choice of treatment arms within each subtrial. Clinical equipoise should increase consent rates while the factorial design is the best way to identify interactions.

Conclusion: The multiplex design may evolve naturally from today's research limitations and challenges, while principal objections seem absent. However this new design poses important infrastructural, organisational and psychological challenges that need in depth consideration.
\end{abstract}

Keywords: Trial design, Clinical equipoise, Factorial design, Simultaneous randomization, Interaction, Bias

\section{Background}

Randomised clinical trials (RCT) should provide highlevel evidence. However RCT's often exhibit several important limitations: (A) Clinical equipoise is frequently not present for the interventions that are compared [1]. (B) Patients are often not allowed to participate in multiple trials for mainly non-methodological reasons. (C) The costs to initiate, conduct and successfully conclude trials are high. (D) Trials may only include small proportions of the relevant patients leading to results with low external validity. (E) Frequently, trialists choose surrogate or intermediate outcomes [2,3]. (F) And unrealistic, small sample sizes may be based on inappropriate optimism regarding the expected effect size [3]. All these factors can increase bias and can thus lead to unreliable conclusions [4].

Multiplex trial design may offer benefits including a more ethical and more efficient clinical research methodology.

\section{Findings}

We hypothesize that a novel design, called multiplex, will allow a more ethical and more efficient framework

\footnotetext{
* Correspondence: f.keus@umcg.nl

Department of Critical Care, University of Groningen, University Medical Center Groningen, Groningen, the Netherlands
}

for conducting clinical studies. The principle of multiplexing [5] is widely used in many technical areas. Briefly, it denotes the combination of multiple signals into a single combined continuous signal that later can be decomposed into its individual signals (Figure 1). Clinical trial design could evolve into a similar approach (Figure 2).

The proposed multiplex trial has several key design elements, including a combination of the continuous and factorial approaches (Table 1). Patients are enrolled within a permanent trial structure and at any time point several subtrials will be conducted to address different hypotheses. The multiplex principle includes a factorial design to simultaneously run various subtrials for the same patient category [6,7]. The number of clinical comparisons that are studied will vary over time, depending on the subtrials that are running at any time point. For all subtrials a relevant outcome according to Grading of Recommendations Assessment Development and Evaluation (GRADE) [2] is used. For example in critical care many interventions could be assessed for the agreed-upon outcome, i.e. hospital mortality. Enforcing clinical equipoise between the interventions within each subtrial, and their various combinations 


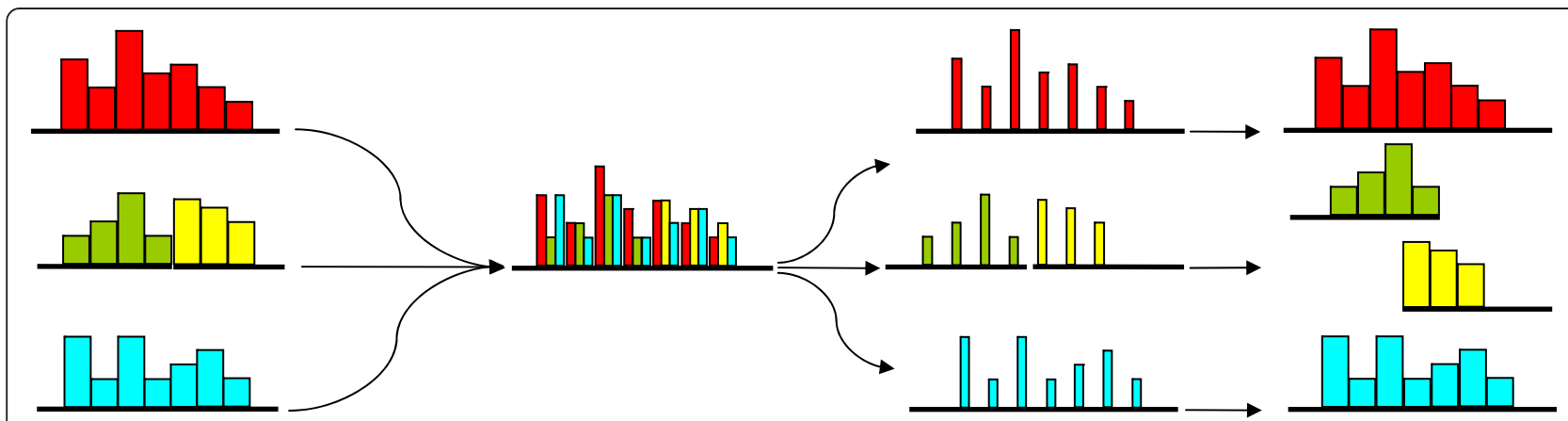

Figure 1 Multiplex communication principle. In communications technology and in other fields multiplexing is used to combine multiple independent packages of information into a continuous single signal that after transmission can be decomposed into the original information packages.

justifies that patients are simultaneously included in multiple subtrials. Such a design will result in increased efficiency as patients are randomised for multiple subtrials simultaneously and because of the continuous nature. It may demonstrate robust detection of interactions, increased patient consent by respecting equipoise and increased generalisability of results by using fewer exclusion criteria (Table 1).

\section{Key elements of multiplex design}

(A) The condition of clinical equipoise is often not met by the interventions that are compared [8], for example because of an inappropriate control arm [9]. Freedman [1] proposed that 'clinical equipoise' should be based on present or imminent controversy in the clinical community over which treatment would be the preferred treatment. Thus this requirement is satisfied if there is genuine uncertainty within the expert medical community - not necessarily on the part of the individual investigator about the preferred treatment [1]. For example, clinicians could be evenly divided whether epinephrine or norepinephrine would be optimal for a specific condition.

Despite strong debates, the universal nature of this ethical bedrock of trials cannot be ignored $[8,10]$. Respecting clinical equipoise may well result in smaller expected differences in outcome. Consequently, the sample size estimation would be larger to adequately address the question of the subtrial.

(B) Patients do usually not participate in more than one trial. Competitive motives, more than scientific or patients' interests, may explain this phenomenon. A patient who participates in several subtrials at the same time will contribute to several clinical questions in parallel and thus the costs per subtrial will decrease. In real life, patients who receive $N$ different simultaneous treatments are thus subjected to a multitude, i.e. $N \cdot(N-1)$ of potential interactions. Interactions may remain undetected after approval and market launch $[11,12]$. If possible, interactions ought to be identified during a trial, rather than many years after introduction of drugs or interventions into clinical practice. In case that a certain combination of treatments from different subtrials is known a priori to be undesired, such a particular combination could be excluded in the multiplex design.

(C) Currently the planning, initiation, conduct, conclusion and analysis of individual trials are associated with large costs. In contrast, the multiplex organisational and logistical structure - because of its permanent nature does not need to be rebuilt once it has been established. Conducting randomisation superimposed on an existing registry was demonstrated to result in an important reduction in costs [13].

(D) Regarding inclusion criteria, many trials only include a small proportion of all eligible patients, when reported. Extensive use of exclusion criteria creates trial results applicable only for selected cases. Trials need to produce results which can be generalized to clinical practice by adopting wide inclusion criteria, and limited exclusion criteria [14]. Included patients need to represent the large majority of eligible patients. The multiplex trial design adopts wide inclusion criteria and as few exclusion criteria as possible. Within this framework, subgroup analyses may eventually reveal hypotheses for more or less favourable effects in specific patient groups.

(E) Concerning outcome, less important measures such as continuous outcomes and surrogate outcomes are frequently used, something mainly based on doctors' or hospital's interests (e.g. costs or hospital stay). GRADE emphasizes that outcome measures need to be ranked from to the perspective of the patient [2]. The multiplex trial design was conceived according to this principle: simple and robust outcomes such as mortality and (severe) adverse events that are most relevant to patients.

(F) Unfortunately, many trial sizes are too small to detect relevant statistical differences. Unwarranted optimism 


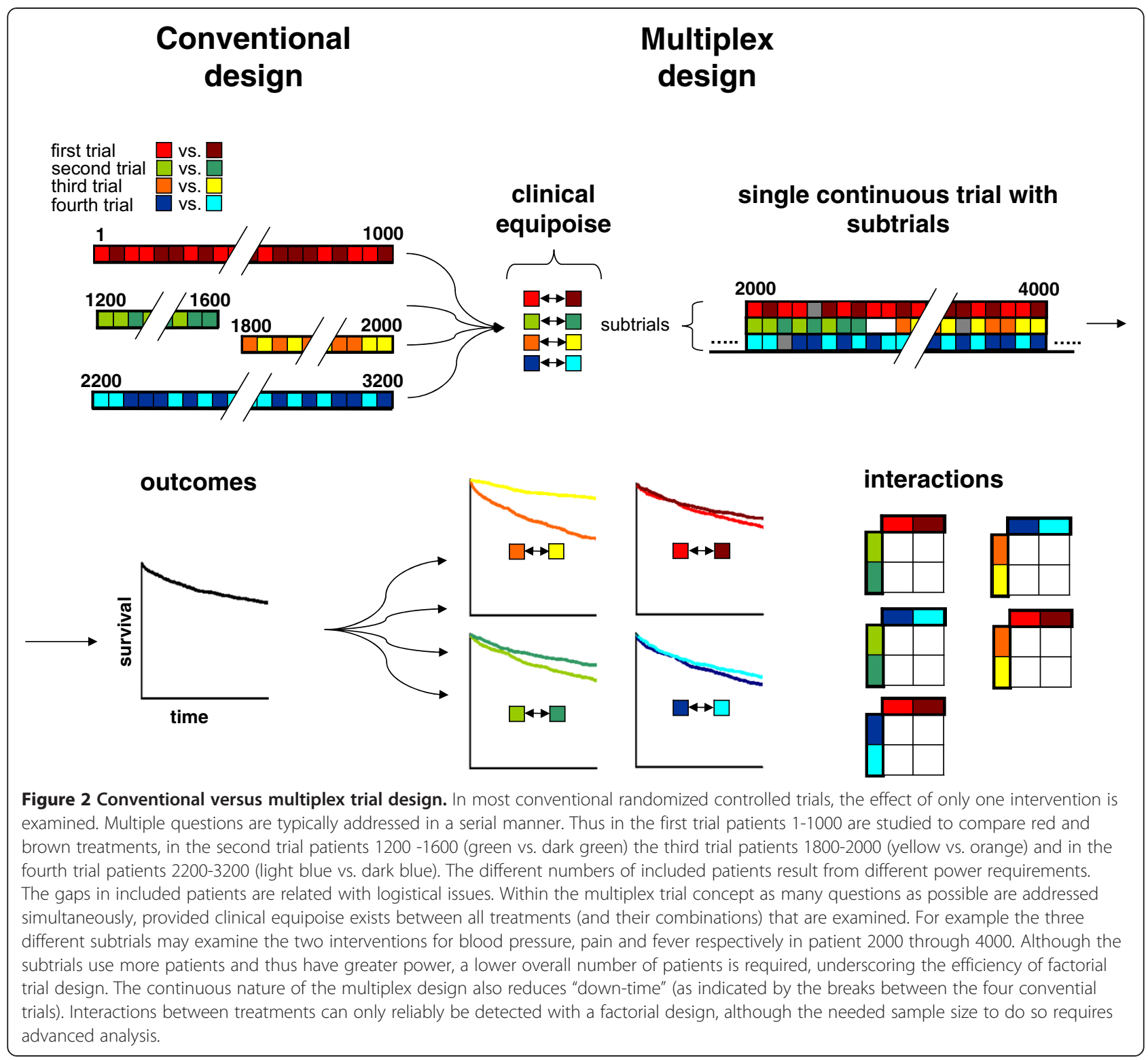

concerning intervention effects or the use of inappropriate surrogate outcomes are sometimes employed to justify small sample sizes. This may lead to false positive or false negative conclusions. There is considerable evidence that the majority of trials are underpowered, so definitive conclusions cannot be drawn for many clinical questions [15]. Usually far more randomised patients are needed before clinical questions can reliably be answered, and even more so when truly equivalent interventions are compared since differences will be smaller. Multiplex trial design therefore must entail large(r) sample sizes [16].

\section{Discussion}

The combination of a continuous and factorial trial with clinical equipoise between all interventions, requires that each subtrial should be designed with low risks of bias and sufficiently large sample sizes based on realistic intervention effects focusing on outcome measures according to GRADE $[2,4,15,17]$.

Key elements of the multiplex design interact: both equipoise and choosing relevant outcomes inevitably lead to larger sample sizes as hypothesized differences in intervention effects will be smaller. This effect, however, will be offset by higher efficiency due to simultaneous randomisation of patients in multiple subtrials. A critical multiplex advantage is that only factorial studies can detect interactions $[7,18]$. Since equipoise and quality are central principles of the proposed multiplex design, we believe that patient's confidence and consent will increase. 
Table 1 Key elements, requirements and additional benefits of multiplex trial design

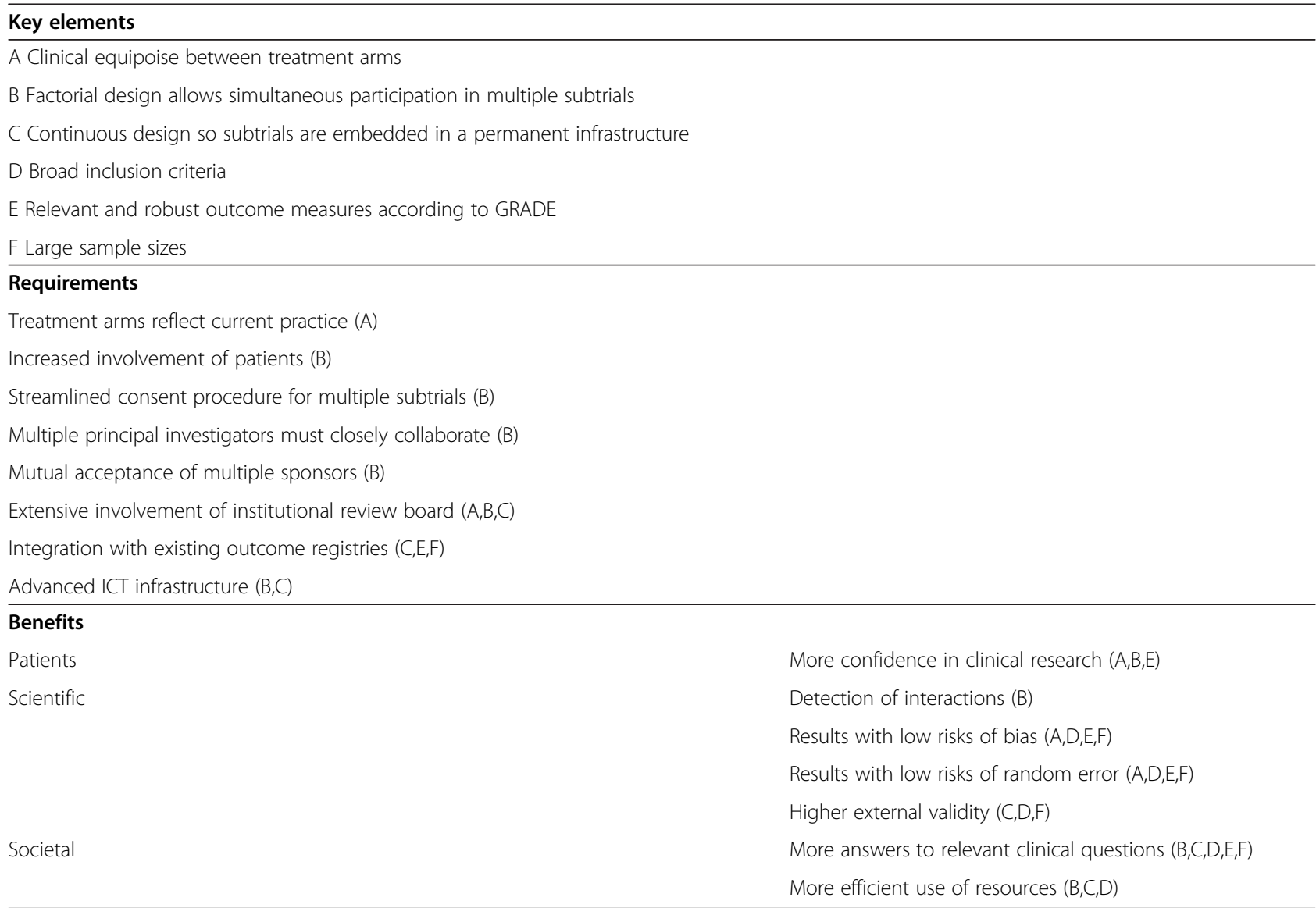
Summary of the components of the multiplex concept (A through F) and the various requirements as well as further benefits that we foresee that are related with these components.

Organisational issues as well as the willingness of investigators to cooperate must be addressed if multiplex is to succeed. Informed consent for multiple subtrials must be condensed into a single transparent informed consent procedure. Attitudes toward intellectual and material ownership of trials need to change fundamentally. Funding of multiplex trial units may originate from sponsors such as health service providers, drug and device industries, as well as clinical investigators. Although sponsors will have to relinquish part of their control of trials [19], in return the required resources would be borne by multiple sponsors. Ownership of trials as well as which subtrials are prioritized should be reconsidered as well as who will manage a multiplex institute. We believe that many registries (e.g. for cardiology or critical care) that currently record outcome on a nation-wide basis might provide part of the infrastructure for conducting multiplex trials. Modern information technology and web-based applications may offer solutions for data registration as well as transparency towards patients. Large sample sizes inevitably demand a multi-centre approach and probably the organisational structure will expand beyond national boundaries, creating additional legal challenges. Although these and other yet unthoughtof issues must all be addressed before we can embark upon such a complex enterprise, we firmly believe that the multiplex trial design is a natural direction trial design must evolve into.

\section{Conclusion}

We believe that the multiplex design is compatible with basic ethical principles and that it is a natural methodological direction that trial design should evolve into. Obviously, considerable psychological, organizational and regulatory hurdles have to be overcome before multiplex trial design becomes reality.

\section{Competing interests}

The authors declare that they have no competing interests.

\section{Authors' contributions}

All three authors contributed to this debate paper. All authors read and approved the final manuscript. 


\section{Acknowledgements}

We wish to thank Christian Gluud, Karim Mahmoud, Wim Sluiter and Felix

Zijlstra for their comments.

Received: 10 February 2014 Accepted: 30 July 2014

Published: 14 August 2014

\section{References}

1. Freedman B: Equipoise and the ethics of clinical research. $N$ Engl J Med 1987, 317:141-145.

2. Guyatt GH, Oxman AD, Kunz R, Vist GE, Falck Ytter Y, Schünemann HJ, GRADE Working Group: What is "quality of evidence" and why is it important to clinicians? BMJ 2008, 336:995-998

3. Halpern SD, Karlawish JHT, Berlin JA: The continuing unethical conduct of underpowered clinical trials. JAMA 2002, 288:358-362

4. Savović J, Jones H, Altman D, Harris R, Jüni P, Pildal J, Als-Nielsen B, Balk EM, Gluud C, Gluud LL, loannidis JP, Schulz KF, Beynon R, Welton NJ, Wood L, Moher D, Deeks JJ, Sterne JA: Influence of reported study design characteristics on intervention effect estimates from randomized, controlled trials. Ann Intern Med 2012, 157:429-438.

5. Wikipedia - Multiplexing. [http://en.wikipedia.org/wiki/Multiplexing]

6. Montgomery AA, Peters TJ, Little P: Design, analysis and presentation of factorial randomised controlled trials. BMC Med Res Methodol 2003, 3:26.

7. Green S, Liu PY, O'Sullivan J: Factorial design considerations. J Clin Oncol 2002, 20:3424-3430.

8. Fries JF, Krishnan E: Equipoise, design bias, and randomized controlled trials: the elusive ethics of new drug development. Arthritis Res Ther 2004, 6:R250-R255.

9. Felson DT, Glantz L: A surplus of positive trials: weighing biases and reconsidering equipoise. Arthritis Res Ther 2004, 6:117-119.

10. Veatch RM: The irrelevance of equipoise. J Med Philos 2007, 32:167-183,

11. Causevic-Ramosevac A, Semiz S: Drug interactions with statins. Acta Pharm 2013, 63:277-293.

12. Stone GW, Maehara A, Witzenbichler B, Godlewski J, Parise H, Dambrink JH, Ochala A, Carlton TW, Cristea E, Wolff SD, Brener SJ, Chowdhary S, El-Omar M, Neunteufl T, Metzger DC, Karwoski T, Dizon JM, Mehran R, Gibson CM, INFUSE-AMI Investigators: Intracoronary abciximab and aspiration thrombectomy in patients with large anterior myocardial infarction: the INFUSE-AMI randomized trial. JAMA 2012, 307:1817-1826.

13. Fröbert O, Lagerqvist B, Olivecrona GK, Omerovic E, Gudnason T, Maeng M, Aasa $M$, Angerås $\mathrm{O}$, Calais $\mathrm{F}$, Danielewicz $\mathrm{M}$, Erlinge $\mathrm{D}$, Hellsten $\mathrm{L}$, Jensen $\mathrm{U}$, Johansson AC, Kåregren A, Nilsson J, Robertson L, Sandhall L, Sjögren I, Ostlund O, Harnek J, James SK, TASTE Trial: Thrombus aspiration during STsegment elevation myocardial infarction. N Engl J Med 2013, 369:1587-1597.

14. Yusuf S, Held P, Teo KK, Toretsky ER: Selection of patients for randomized controlled trials: implications of wide or narrow eligibility criteria. Stat Med 1990, 9:73-83.

15. Thorlund K, Imberger G, Walsh M, Chu R, Gluud C, Wetterslev J, Guyatt G, Devereaux PJ, Thabane $L$ : The number of patients and events required to limit the risk of overestimation of intervention effects in meta-analysis-a simulation study. PLoS One 2011, 6:e25491.

16. Yusuf S, Collins R, Peto R: Why do we need some large, simple randomized trials? Stat Med 1984, 3:409-422.

17. Keus F, Wetterslev J, Gluud C, van Laarhoven CJ: Evidence at a glance: error matrix approach for overviewing available evidence. BMC Med Res Methodol 2010, 10:90.

18. McAlister FA, Straus SE, Sackett DL, Altman DG: Analysis and reporting of factorial trials: a systematic review. JAMA 2003, 289:2545-2553.

19. Lundh A, Sismondo S, Lexchin J, Busuioc OA, Bero L: Industry sponsorship and research outcome. Cochrane Database Syst Rev 2012, 12:MR000033.

doi:10.1186/1756-0500-7-530

Cite this article as: Keus et al: More ethical and more efficient clinical research: multiplex trial design. BMC Research Notes 2014 7:530

\section{Submit your next manuscript to BioMed Central and take full advantage of:}

- Convenient online submission

- Thorough peer review

- No space constraints or color figure charges

- Immediate publication on acceptance

- Inclusion in PubMed, CAS, Scopus and Google Scholar

- Research which is freely available for redistribution

Submit your manuscript at www.biomedcentral.com/submit
Ciomed Central 